\title{
Impact of E-bills Payment on Customer Satisfaction in Uganda: Stanbic Bank Uganda Limited as the Case Study
}

\author{
Sazir Nsubuga Mayanja \\ School of Post Graduate Studies, University of Kigali, Kigali, Rwanda \\ Email address: \\ saznsumay@gmail.com \\ To cite this article: \\ Sazir Nsubuga Mayanja. Impact of E-bills Payment on Customer Satisfaction in Uganda: Stanbic Bank Uganda Limited as the Case Study. \\ Science Journal of Business and Management. Special Issue: Business Policy\& Strategic Management. Vol. 8, No. 3, 2020 , pp. $112-118$. \\ doi: $10.11648 /$ j.sjbm.20200803.12
}

Received: January 6, 2020; Accepted: February 24, 2020; Published: July 4, 2020

\begin{abstract}
The purpose of the study was to examine the effect of e-bill payment on customer satisfaction in Uganda with Stanbic Bank Uganda Limited as the case study. The study involved 5 managers, 10 Middle Level staff involved in E-banking operations, 5 Head office (Stanbic) E-banking operative staff, 8 Customer relationship officers attending walk-in-customers and 63 Customers of Stanbic Bank Uganda Limited. A cross-sectional approach, as well as a combination of quantitative and qualitative data analysis techniques was employed in this study. Quantitative data analysis techniques involved the use of descriptive statistics such as frequencies and percentages to summarize responses on issues of E-bills payment impact on customer satisfaction while the Pearson's correlation coefficient was used to establish the relationship between dimensions of E-bills payment and customer satisfaction as study objectives. Findings indicate that there is a moderate positive relationship between e-bill payment and customer satisfaction; $(\mathrm{r}=0.266 \mathrm{p}=0.016 \mathrm{n}=82)$. The relationship is statistically significant at $95 \%$ confidence level since p-value (Sig.) is less than $0.050(=0.000)$. This implies that improvements in e-bill payment factors shall be related to improvements in customer satisfaction. Findings from descriptive statistics indicated that on average the respondents agreed to the statement that e-bill payment has an effect on customer satisfaction which included capacity to handle a greatly enhanced volume and of payments, far lesser time per bill handles, increased efficiency and accuracy and reduced payment concerns.
\end{abstract}

Keywords: E-payment, Electronic Transfer, Customer Satisfaction, E-banking, Data, Banks, Account

\section{Introduction}

One of the significant innovations of the financial system which has impacted on the way financial transactions are conducted in the area of online payment has been that of the e-bill. Electronic bill payment is a payment process where a customer instructs a financial institution to electronically transfer money from a transaction or credit account to a creditor or vendor such as a public utility or individual, to be credited against a specific debtor account through means of telephone, online or mobile banking. Quite often it is done through a national payment system operated by the banks or in conjunction with the government. Customers benefit from electronic payment of bills because it is cheaper, faster, and more convenient than writing, posting and reconciling cheques. In addition, though limitations exist, a wider range of bank accounts or credit cards can be used for the electronic payment of bills. Using electronic bill presentment and payment enables businesses to fast-track customer payments and get access to funds faster, which in turn results in cash flow and customer relations improvement. [1]

It enables a creditor to present the underlying obligation of the debtor by electronic means, via the website. Consumers no longer have to receive a paper copy of the bill, but can, if they so wish, print it and view archived copies of previous bills, so as to carry out reconciliation with a view to paying electronically and at their convenience. The accuracy of any paper and digital image-based approach is, especially when generated in big volumes, often compromised, which challenge e-billing can significantly reduce through mining compliant master data, using unique identification techniques. E-billing offers opportunity for real-time or near 
real-time data validation, which makes it possible for an earlier rejected incorrect invoice to be rectified for timely processing and payment.

For banks the advantages of electronic bill payments are a reduction in processing costs minimising paperwork and an increase in customer loyalty, among others. In a 2003 study banks observed that customers who pay online show more loyalty and are more receptive to other offers. [2] It has also been noted that from the bank's perspective electronic payments helps them through cost saving, increasing customer base, enabling mass customization for e-Business services, extending marketing and communication channel, searching for new innovation services, as well as exploring and developing of non-core business. [3]. Both consumers and service providers can benefit from e-payment systems leading to increased national competitiveness in the long run. Successful implementation of electronic payment systems depends on how its security and privacy dimensions are perceived by consumers, and how well managed these are will in turn have an impact on the market confidence in the system [4]. A properly conceived and implemented electronic payment system should bring about efficiency, fraud reduction and innovativeness. There are two major types of electronic billing, namely, biller direct and bank-aggregator [5]. Under biller direct, consumers make payments directly to a biller who issues bills received at the issuer's website. In Uganda, the National Water and Sewerage Corporation and the electricity provider, UMEME, adopted this system in collaboration with several commercial banks. Biller direct arrangements have proven attractive. The result is a grand market for outsourced billing providers who specialize in electronic billing processes and technology for companies that need to send bills directly to their customers [6]. As for bank aggregator, payment is made at an aggregator or consolidator site, usually from a consumer's bank website, which enables the consumer to make payments to multiple billers that are pre-registered to receive payments [7].

\section{Customer Satisfaction}

Customer satisfaction is defined as a collection of outcomes of perception, evaluation and psychological reactions to the consumption experience with a product or service. It is a result of a cognitive and affective evaluation with some comparison standard rated against the actually perceived performance. If the performance perceived is less than expected, customers will be dissatisfied. On the other hand, if the perceived performance exceeds expectations, customers will be satisfied or even delighted [8]. Satisfied customers will most certainly come back due to the quality of services they have received and also do one good for the bank by recommending the same bank to friends and family. This helps banks to enlarge their customer base and to generate more sales which eventually enables them to meet their objective of profit maximisation [9]. As such customer satisfaction is a key factor for business owners and marketers of any product or service. Like it is implied in the economics concept of consumer sovereignty, a rising trend of purchases of a product or consumption of a service implies satisfaction, thus guiding an investor as to in which strategic business units more resources are to be allocated [10].

The E-bills (Electronic bills) manner of bills management has taken handling of bills to a new level. It has moved processes from the traditional iterative, tedious and boring pursuit to more challenging and engaging interface, which is also cheaper, executable twenty-four hours of the day and throughout the year. The system requires less time and energy, but requires commitment to continuous professional and technical development on the part of the human resource capital and investment in research and development for the institution to leverage technology. Introduction of electronic billing made it easier to use and new applications and websites are continuously launched to make it easier and reachable for more customers to use it anytime and anywhere [11].

\section{Significance of the Study}

E-bills payments are a relatively recent practice compared to the traditional in-kind, cheque or cash payments in Uganda, as it is in many developing countries. In Uganda, government recognition of the system has enjoyed only a very short span of existence. It was in 1998 that the Bank of Uganda, in its efforts to reduce transactions on cash basis in the country, established the National Payment System Secretariat (NPSS). The major objective was removal or reduction of barriers to the use of electronic and non cash based payments. Currently payment systems and platforms such as electronic cheque clearance, electronic funds transfer (EFT) and real time gross settlement (RTGS) are gaining recognition and being adopted by various stakeholders, but at a slow pace. Because of the recent emergence of government policy regarding use of electronic payments in the country, there is very limited research on electronic payments in general and e- bills payment in particular. In this research attempt has been done to identify, measure and evaluate factors of e-bill payments which motivate or alternatively discourage customers. This way the research will among others help policy makers, investors, researchers and other stakeholders in appreciating how to leverage the innovation for their benefit and for the general good.

\section{Conceptual Framework}

A conceptual framework is an interconnected set of ideas (theories) about how a particular phenomenon functions or is related to its parts and it serves as the basis for understanding the causal or correlational patterns of interconnections across events, ideas, observations, concepts, knowledge, interpretations and other components of experience [12]. The conceptual framework offers many benefits to a research. It helps in identifying and constructing the researcher's worldview on the phenomenon to be investigated [13] 
Independent Variable

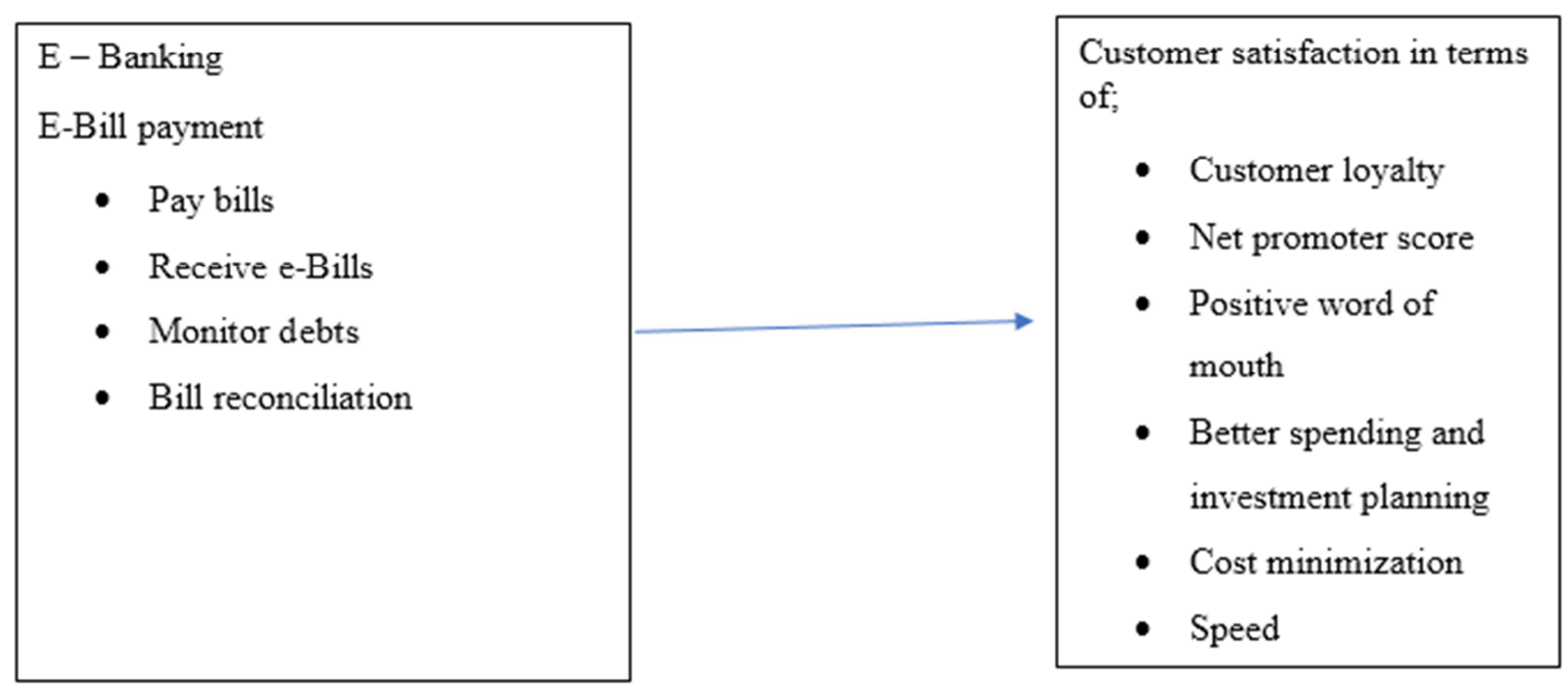

\section{Dependent Variable}

Source: researcher

Figure 1. Conceptual Framework Source: 2018.

The elements of independent variables cause dependent variables to behave in a give way. For example, timely generation of accurate bills, promptly submitted to debtor clients enables them to plan their cash flows from an informed position, generating satisfaction among the stakeholders.

\section{Research Methodology}

In this section the researcher presents the methods and procedures for conducting this study in the following sections: research design, area of study,; study population, sampling procedures, data collection methods and instruments, quality control methods, data management and processing, data analysis, and ethical considerations.

\subsection{Research Design}

Research design is the conceptual structure within which research is conducted. It constitutes the blueprint for the collection, measurement and analysis off data. It includes an outline of what the researcher did from writing the hypothesis or research question and its operational implications to the final analysis of data [14]. The researcher used a crosssectional approach which involved collecting data at once, from employees of Stanbic Bank Uganda Limited head office in Kampala Capital City and customers. This investigation was based on a case study of Stanbic Bank Uganda Limited, Head office in Kampala Capital City. The reasons of using a case study were that, it was a good source of ideas about behavior, it was a good method to study rare phenomena and it was a good method to challenge theoretical assumptions.

\subsection{Study Population}

The target population of this study comprised of employees of Stanbic Bank Uganda Limited at the head office and some customers that visited the branch in the same location. According to the Head of Human Resources of the bank, Head office on crested towers was the biggest branch of Stanbic Bank Uganda Limited with over 110 employees.

\subsection{Determination of Sample Size}

This sample size was chosen as per guidance below.

Table 1. Showing the sample size of the respondents.

\begin{tabular}{lll}
\hline & $\begin{array}{l}\text { Target } \\
\text { population }\end{array}$ & $\begin{array}{l}\text { Sample } \\
\text { size }\end{array}$ \\
\hline Managers & 5 & 5 \\
Middle Level staff & 10 & 10 \\
E-banking operative staff & 5 & 5 \\
Customer relationship officers & 8 & 8 \\
Customers of Stanbic Bank Uganda Limited. & 75 & 63 \\
Total & 103 & 91 \\
\hline
\end{tabular}

Source: Krejcie, Robert V., Morgan, Daryle W., "Determining Sample Size for Research Activities”, Educational and Psychological Measurement, 1970.

The study involved 5 managers, 10 Middle Level staff involved in E-banking operations, 5 Head office (Stanbic) Ebanking operative staff, 8 Customer relationship officers attending walk-in-customers and 63 Customers of Stanbic Bank Uganda Limited.

\subsection{Sampling Techniques and Procedures}

Both probability and non-probability sampling techniques were employed in the study. The probability technique of proportional stratified random sampling was used in selecting employees to participate in the study. Proportional stratified random sampling involves dividing the population into mutually exclusive and exhaustive strata, and then selecting a 
random sample of subjects which is proportional to size of a given stratum. The non-probability technique of purposive sampling was also used.

\subsection{Data Collection Methods and Instruments}

Questionnaires and field guides were used. Questionnaire survey involved collecting quantitative data from selected employees and customers of Stanbic Bank Uganda Limited. The researcher obtained written permission from the bank's administration to interview respondents. The researcher then employed a combination of data collection methods including questionnaire survey, key informant interviews, and documentary review. Questionnaires were used because they were cost-efficient to gather quantitative data. Apart from being inexpensive and flexible, questionnaires were also a practical way to gather data. They were targeted to groups chosen and were managed very well. The major study variables were measured using structured close-ended items adopted from previous research studies and assessed using a five-point Likert scale ranging from $1=$ strongly disagree to $5=$ strongly agree. Close-ended questions were used.

Employees and customers were given questionnaires and requested to fill them within a specified time period, and were collected from the respondents upon completion. Key informant interviews involved collecting qualitative data through in-depth face-to-face engagements with selected heads of department of Stanbic Bank Uganda Limited departments in the bank to compliment data obtained through questionnaire surveys.

Both probability and non-probability sampling techniques were employed in the study. The probability technique of proportional stratified random sampling was used in selecting employees to participate in the study. Proportional stratified random sampling involves dividing the population into mutually exclusive and exhaustive strata, and then selecting a random sample of subjects which is proportional to size of a given stratum. In the case of this study, employees were grouped into 5 strata based on their respective work responsibilities and a sample of employees was drawn from each department, which was proportional to the number of employees in each department. The technique was preferred because the number of employees varied across the bank departments; therefore, it was used to ensure fair representation of employees from the respective departments in the sample. The non-probability technique of purposive sampling was also used in selecting the 5 Managers of the departments that participated in the study. These individuals were chosen because they were assumed to be highly knowledgeable about issues of E-banking and customer satisfaction in the bank; and therefore, their opinions are important for purposes of comparison with employees' views.

\subsection{Data Analysis}

A combination of quantitative and qualitative data analysis techniques was employed in this study. Quantitative data analysis techniques involved the use of descriptive statistics such as frequencies and percentages to summarize responses. Pearson's correlation coefficient was used to establish the relationship between dimensions of E-banking and customer satisfaction as specified in the study objectives.

\subsection{Tabular Presentation}

The researcher used tables, as appropriate, for presentation of data in form of frequency, percentages and standard deviation to indicate the number of occurrence of responses to particular questions statically. SPSS software was used to analyse data and the presentations were in tables, with a view to provide clear understanding of the research interpretations for clear and easy understanding of the phenomenon studied

\section{Presentation, Analysis and Interpretation of Findings}

This section presents an analysis and interpretation of empirical findings in reference to the research objective set out earlier.

Table 2. Employee views on E-Bill Payment.

\begin{tabular}{|c|c|c|c|c|c|c|c|c|}
\hline & $\mathbf{N}$ & SDA & DA & NS & $\mathbf{A}$ & $\mathbf{S A}$ & Mean & Std. Deviation \\
\hline More bills are being paid through & 32 & & & $6 \%(2)$ & $41 \%(13)$ & $53 \%(17)$ & 4.47 & .621 \\
\hline Bill efficiency is realized & 32 & & & $6 \%(2)$ & $34 \%(11)$ & $59 \%(19)$ & 4.53 & .621 \\
\hline Bill payment has become easier & 32 & & & $3 \%(1)$ & $34 \%(11)$ & $63 \%(20)$ & 4.56 & .669 \\
\hline Bill payment concerns have reduced & 32 & & $3 \%(1)$ & $3 \%(1)$ & $41 \%(13)$ & $53 \%(17)$ & 4.44 & .716 \\
\hline Bill payment turnaround time has improved & 32 & & $3 \%(1)$ & $6 \%(2)$ & $38 \%(12)$ & $53 \%(17)$ & 4.41 & .756 \\
\hline Less time in bill payment is realized & 32 & & & $3 \%(1)$ & $38 \%(12)$ & $59 \%(19)$ & 4.53 & .671 \\
\hline
\end{tabular}

Source: Field Primary Data

Key: $\mathrm{SD}=$ strongly disagree, $\mathrm{D}=$ Disagree, $\mathrm{NS}=$ Not sure, $\mathrm{A}=$ Agree, $\mathrm{SA}=$ strongly agree

From table 2 above, the respondents were asked whether more bills are being paid through.

The results from the study revealed that, of the total respondents, $53 \%$ strongly agreed, while $41 \%$ agreed, $6 \%$ were neutral, while $0 \%$ disagreed and $0 \%$ strongly disagreed. This implies that the majority, $94 \%$ of the respondents were in agreement as shown by the statistics, with a mean of 4.47 and SD of 0.621 . The above statistics implied that with $94 \%$ in agreement in comparison to the $0 \%$ who disagreed this is a factor which should be uphold by the stakeholders. The above findings show that bank stakeholders shows that should uphold this aspect.

In order to find out whether, Bill efficiency is realized; respondents were asked to state the extent to which they 
agreed with the above. Of the total respondents, 59\% strongly agreed, while $34 \%$ agreed, $7 \%$ were neutral, while $0 \%$ disagreed and $0 \%$ strongly disagreed. This implies that the majority, $93 \%$ of the respondents were in approval, with a mean of 4.53 and SD of 0.621 . From the statistics above with $2 \%$ neutral this is an aspect to upheld stakeholders in comparison to the $0 \%$ who were in disagreement. From the findings above this shows that to deliver on e-banking this aspect should upheld by the stakeholders.

From the findings of the study the respondents were asked about Bill payment has become easier. Of the total respondents, $63 \%$ strongly agreed, while 34\% agreed, 3\% were neutral, while $0 \%$ disagreed and $0 \%$ strongly disagreed. This implies that the majority, $97 \%$ of the respondents were in approval with a mean of 4.56 and SD of 0.669 from the statistics above, this shows that this is a key attribute which should be upheld by the bank stakeholders.

The respondents were asked about Bill payment concerns have reduced. The results from the study revealed that, of the total respondents, $53 \%$ strongly agreed, while $41 \%$ agreed, $3 \%$ were neutral, while $3 \%$ disagreed and $0 \%$ strongly disagreed. This implies that the majority, $94 \%$ of the respondents were in agreement as shown by the statistics, with a mean of 4.44 and SD of 0.716 . The different statistics implied that this is a good aspect to be upheld by the bank stakeholders.

In determining whether the Bill payment turnaround time has improved, the study revealed that; of the total respondents, 53\% strongly agreed, while 38\% agreed, and $6 \%$ were neutral, while $3 \%$ disagreed and $0 \%$ strongly disagreed. This implies that the majority, $91 \%$ of the respondents were in agreement with a mean of 4.41 and $\mathrm{SD}$ of 0.756 . From the findings above implied that this is a good aspect to be upheld by the bank stakeholders. The above findings show that stakeholders should uphold this aspect.

In order to find out whether, less time in bill payment is realized; respondents were asked to state the extent to which they agreed with the above. Of the total respondents, 59\% strongly agreed, while 38\% agreed, $3 \%$ were neutral, while $0 \%$ disagreed and $0 \%$ strongly disagreed. This implies that the majority, $97 \%$ of the respondents were in approval, with a mean of 4.53 and SD of 0.671 . From the statistics above with $97 \%$ in agreement this is a positive aspect to the bank management in comparison to the $0 \%$ who were in disagreement. From the findings above this shows that to deliver on the e-banking initiatives this concern should be upheld.

Table 3. Customer views on E-Bill Payment.

\begin{tabular}{|c|c|c|c|c|c|c|c|c|}
\hline & $\mathbf{N}$ & SDA & DA & NS & $\mathbf{A}$ & $\mathbf{S A}$ & Mean & Std. Deviation \\
\hline You pay your Bills through E-bill payment & 50 & $2 \%(1)$ & $0 \%$ & $6 \%(3)$ & $58 \%(29)$ & $34 \%(17)$ & 4.22 & .737 \\
\hline Bill efficiency is realized & 50 & & $2 \%(1)$ & $4 \%(2)$ & $50 \%(25)$ & $44 \%(22)$ & 4.36 & .663 \\
\hline Bill payment has become easier & 50 & & $4 \%$ & $2 \%(1)$ & $52 \%(26)$ & $42 \%(21)$ & 4.32 & .713 \\
\hline you satisfied with bill payment & 50 & & & $4 \%(2)$ & $56 \%(28)$ & $40 \%(20)$ & 4.36 & .563 \\
\hline Bill payment turnaround time has improved & 50 & & & $10 \%(5)$ & $38 \%(19)$ & $52 \%(26)$ & 4.42 & .673 \\
\hline Less time in bill payment is realized & 50 & & & $6 \%(3)$ & $50 \%(25)$ & $44 \%(22)$ & 4.38 & .602 \\
\hline
\end{tabular}

Source: Field Primary Data

Key: $\mathrm{SD}=$ strongly disagree, $\mathrm{D}=$ Disagree, $\mathrm{NS}=$ Not sure, $\mathrm{A}=$ Agree, $\mathrm{SA}=$ strongly agree

From table 3 above, the respondents were asked whether my bills are being paid through e-bill payment. The results from the study revealed that, of the total respondents, $34 \%$ strongly agreed, while $58 \%$ agreed, $6 \%$ were neutral, while $0 \%$ disagreed and $2 \%$ strongly disagreed. This implies that the majority, $94 \%$ of the respondents were in agreement as shown by the statistics, with a mean of 4.22 and SD of 0.737. The above statistics implied that with $92 \%$ in agreement in comparison to the $0 \%$ who disagreed this is a factor which should be uphold by the stakeholders. The above findings show that bank stakeholders should uphold this aspect.

In order to find out whether, Bill efficiency is realized; respondents were asked to state the extent to which they agreed with the above. Of the total respondents, $44 \%$ strongly agreed, while $50 \%$ agreed, $4 \%$ were neutral, while $2 \%$ disagreed and $0 \%$ strongly disagreed. This implies that the majority, $93 \%$ of the respondents were in approval, with a mean of 4.36 and SD of 0.663 . From the statistics above with $2 \%$ neutral this is an aspect to upheld stakeholders in comparison to the $0 \%$ who were in disagreement. From the findings above this shows that to deliver on e-banking this aspect should be upheld by the stakeholders.

From the findings of the study the respondents were asked about Bill payment has become easier. Of the total respondents, $42 \%$ strongly agreed, while $52 \%$ agreed, $2 \%$ were neutral, while $4 \%$ disagreed and $0 \%$ strongly disagreed. This implies that the majority, $97 \%$ of the respondents were in approval with a mean of 4.32 and SD of 0.713 from the statistics above, this shows that this is a key attribute which should be upheld by the bank stakeholders.

The respondents were asked about you satisfied with bill payment. The results from the study revealed that, of the total respondents, $40 \%$ strongly agreed, while 56\% agreed, $4 \%$ were neutral, while $0 \%$ disagreed and $0 \%$ strongly disagreed. This implies that the majority, $96 \%$ of the respondents were in agreement as shown by the statistics, with a mean of 4.36 and SD of 0.563 . The different statistics implied that this is a good aspect to be upheld by the bank stakeholders.

In determining whether the Bill payment turnaround time has improved, the study revealed that; of the total respondents, 52\% strongly agreed, while 38\% agreed, and $10 \%$ were neutral, while $0 \%$ disagreed and $0 \%$ strongly disagreed. This implies that the majority, $91 \%$ of the 
respondents were in agreement with a mean of 4.42 and SD of 0.673. From the findings above implied that this is a good aspect to be upheld by the bank stakeholders. The above findings show that stakeholders should uphold this aspect.

In order to find out whether, less time in bill payment is realized; respondents were asked to state the extent to which they agreed with the above. Of the total respondents, $44 \%$ strongly agreed, while $50 \%$ agreed, $6 \%$ were neutral, while $0 \%$ disagreed and $0 \%$ strongly disagreed. This implies that the majority, $97 \%$ of the respondents were in approval, with a mean of 4.38 and SD of 0.602 . From the statistics above with $94 \%$ in agreement this is a positive aspect to the bank management in comparison to the $0 \%$ who were in disagreement. From the findings above this shows that to deliver on the e-banking initiatives this concern should be upheld.

Table 4. Correlation matrix for e-bill payment and customer satisfaction.

\begin{tabular}{llll}
\hline Correlations & & & \\
\hline & & E-bill payment & Customer satisfaction \\
& Pearson Correlation & 1 & $.266^{*}$ \\
E-bill payment & Sig. (2-tailed) & .016 & 82 \\
& $\mathrm{~N}$ & 82 & $.266^{*}$ \\
Customer satisfaction & Pearson Correlation & .016 & 82 \\
& Sig. (2-tailed) & $\mathrm{N}$ & 82 \\
\hline
\end{tabular}

*. Correlation is significant at the 0.05 level (2-tailed).

Table 4 shows that there is a moderate positive relationship between e-bill payment and customer satisfaction; $(r=0.266$ $\mathrm{p}=0.016 \mathrm{n}=82)$. The relationship is statistically significant at $95 \%$ confidence level since p-value (Sig.) is less than 0.050 $(=0.000)$. This implies that improvements in e-bill payment factors shall be related to improvements in customer satisfaction. Similarly decline in e-bill payment shall be related to decline in customer satisfaction.

The above research findings from correlation analysis have established that e-bill payment have a weak positive statistically significant relationship with customer satisfaction. There are similar findings in similar researches. In a study of a utility company in Kenya, that is, e-billing service timeliness is crucially vital for customer satisfaction.
The responsiveness of the system both to the customer and the utility company as well as the ability to dispatch lots of bills in a timely manner made customer to conveniently effect payments [15]. In in another study it was found that customers informed through short text messages informing them of amounts due for payment were satisfied and positively responsive.[16]

Regression analysis was used to establish the extent to which e-bill payment affects satisfaction. Therefore, the hypothesis was stated that e-bill payment positively influences customer satisfaction. The coefficient of determination ( $\mathrm{R}$ Square) was used and the results are presented in the table below.

Table 5. Model Summary.

\begin{tabular}{|c|c|c|c|c|c|c|c|c|c|}
\hline \multirow{2}{*}{ Model } & \multirow{2}{*}{$\mathbf{R}$} & \multirow{2}{*}{ R Square } & \multirow{2}{*}{$\begin{array}{l}\text { Adjusted R } \\
\text { Square }\end{array}$} & \multirow{2}{*}{$\begin{array}{l}\text { Std. Error of } \\
\text { the Estimate }\end{array}$} & \multicolumn{5}{|l|}{ Change Statistics } \\
\hline & & & & & R Square Change & F Change & df1 & df2 & Sig. F Change \\
\hline 1 & $.266^{\mathrm{a}}$ & .071 & .059 & .59526 & .071 & 6.104 & 1 & 80 & .016 \\
\hline
\end{tabular}

a. Predictors: (Constant), E-bill payment

Table 5 shows that the coefficient of determination (Adjusted R Square) is 0.059 . This implies that E-bill payment accounts for $36.8 \%$ of the variance in customer satisfaction there are therefore other factors outside E-bill payment that contribute to the greater percentage of customer satisfaction. Whatever the factors are, potential for personalisation of paper bills is limited, and they limit interaction between creditor and debtor, that is, a customer in need of cross checking information with respect to a paper bill must make a telephone call or physically move to make the inquiry, which is more costly in monetary terms and inconveniencing. On the other hand, internet billing ensures instantaneous receipt of information, and has when adopted, fundamentally changed the way companies interact with their customers, with additional services including customer selfcare, automated sales one-to- one marketing. The internet bill will become the gateway through which customers and companies have electronic one to one dialog [17]
In a study to identify and classify common sources of satisfaction and dissatisfaction associated with the use of mobile payment and e-bill settlement, and compare them with determinants of satisfaction with technology-based services, overall findings indicated that the main sources of satisfaction in this context were convenience, ability to deliver the expected function, ability to guarantee secure transactions and function when other payment methods fail. It was convenience, which was found to be the greatest satisfaction source, has been described as the ability to conduct payments quickly, easily and independent of the possession of cash and cards. [18] Dispute handling can be conducted in a more structured way by using the same electronic communication channel. As a result of the increased electronic interaction, the trading partner administration costs can be reduced substantially. [19]

Overall for an economy, it has been observed that a safe and efficient payment system helps to maintain financial 
stability by preventing or containing systemic risks, thus the efforts of the government of Uganda to put in place payment systems among the core functions to achieve and maintain financial stability, support open market operations as a monetary policy transmission mechanism, and to maintain confidence in the national monetary unit - in terms of its value (monetary policy) and circulation (payment systems) [20].

\section{Conclusion and Recommendations}

Findings from descriptive statistics indicated that on average the respondents agreed to the statement that e-bill payment has an effect customer satisfaction which included capacity to handle a greatly enhanced volume and of payments, far lesser time per bill handles, increased efficiency and accuracy and reduced payment concerns. Further findings indicated that there was a weak statistically significant positive relationship between e-bill payment and customer satisfaction. It was further established that there were some lessons learnt from the study to be upheld, which include; quick checking of account balances, easy access of account history, increased efficiency in account management, customer touch points are user friendly. It has been noted that a growing body of evidence demonstrates that e-payment services, not only make financial transactions more affordable, efficient, and transparent, but also build the capacity of individuals to power their own financial future. Form the benefits of e-bill payments noted from this and similar studies, e-bill payment should be encouraged, and ebill payment turnaround time should be improved. These should be achieved with efficiency.

It has been noted above that e-bill payment accounts for only $36.8 \%$ of the variance in customer satisfaction. The big $63.2 \%$ is accounted for by other factors outside E-bill payment, and this gives a challenge and need for research in these other factors that contribute to customer satisfaction.

\section{References}

[1] Improving customer satisfaction and cash flow with electronic Bill Presentment and Payment. A presentation during a workshop at the CeBIT Future of Payments Conference in October 2012: http://www.ippayments.com/site/

[2] Kaplan J (2016) The inventor of customer satisfaction surveys is sick of them, too. Bloomberg News, May 5.

[3] Kumar V, Dalla Pozza I, Ganesh J (2013) Revisiting the satisfaction-loyalty relationship: empirical generalizations and directions for future research. Journal of Retailing 89 (3): 246-262. M

[4] Hariomi Tyagi, Abhishiek Shukla (2016): The Study of Electronic Payment Systems, International Journal of Advanced Research in Computer Science and Software Engineering, Volume 6, Issue 7, July 2016 ISSN: 2277 128X Research Paper

[5] Oladeji, K. (2014). Integrated Personnel and Payroll Information Systems (IPPIS) for Universities and other Higher
Institutions of Learning. A paper presentation at Northwest University, Kano - Nigeria

[6] https://www.aitegroup.com/report/biller-direct-and-walk-billpay-update.

[7] https://en.wikipidia.org/wiki/electronic_billing\#cite_notes

[8] Oladeji F. AGBETOKUN (2018): INTERNET MARKETING PRACTICES AND CUSTOMER LOYALTY: EMPIRICAL EVIDENCE FROM OGUN STATE, NIGERIA, International Journal of Finance and Accounting Volume VIII/2018 ISSN 2344-102X Issue (XVIII) / October 2018 ISSN-L 2344-102

[9] Wikhamn, W. (2019): Innovation, sustainable HRM and customer satisfaction. International Journal of Hospital Management. 2019, 76, 102-110

[10] Jamal, A. (2014). Retail banking and customer behaviour: a study of self concept, satisfaction and technology usage. The International Review of Retail, Distribution and Consumer Research. Vol 2, Issue 1, pp 76-81

[11] Abdallah (Mohd Rawhi) Shaker AL-Ashqar (2018): The impact of Electronic bills on customer satisfaction: a field study on Efawateercom users. Thesis Submitted in Partial Fulfilment of the Requirements for Master Degree in EBusiness, Management Department, Business Faculty Middle East University June 2018

[12] Marilla D. Svinicki (2010): A Guidebook on Conceptual Frameworks For Research In Engineering Education, Rigorous Research in Engineering Education NSF DUE0341127, DUE-0817461, 2010

[13] C Grant (2013) Understanding, Selecting, and Integrating a Theoretical Framework in Dissertation Research: Creating the Blue print for 'House'. Administrative Issues Journal: Connecting Education, Practice and Research, Pp. 12-22 DOI: 10.5929/2014.4.2.9, Banking Journal Volume 3, Issue 2, 2013

[14] Kothari, C. R. (2004). Research Methodology, methods and techniques (2nd ed.). India, Jaipur: New Age International limited publishers

[15] J. I. Perere (2016): EFFECT OF ELECTRONIC BILLING SERVICE ON CUSTOMER SATISFACTION AT KENYA POWER COMPANY A CASE OF NAKURU COUNTY, KENYA, International Journal of Economics, Commerce and Management Vol. IV, Issue 4, April 2016

[16] Kiarie, M. F. (2014). Technological innovation and customer satisfaction in Kenya power and lighting company limited. MBA Project, University Of Nairobi, Kenya

[17] Muzhir Shaban, Rabah Noory, Dua'a Yaseen (2012) Billing System Design Based on Internet Environment (IJACSA) International Journal of Advanced Computer Science and Applications, Vol. 3, No. 9, 2012

[18] Aleksandra Smolarczyk (2018) Customer satisfaction with mobile payments, Thesis in partial fulfilment for the award of the Degree Master of Science (Economics and Business Administration) Degree programme Marketing, Aalto University

[19] C B. Koch (2017): Business Case E-Invoicing / E-Billing, Billentis

[20] Republic of Uganda, National Payment System (NPS) Policy Framework, (2017) 